\title{
One-dimensional coordination polymers based on cobalt(II) and nickel(II))
}

\author{
A. K. Seguin,, ${ }^{1,2}$ C. Cruz, ${ }^{1,2}$ D. Venegas-Yazigi' ${ }^{2,3}$ and V. Paredes-García ${ }^{1,2}$ \\ ${ }^{1}$ Universidad Andres Bello, Departamento de Ciencias Químicas, Santiago, Chile \\ ${ }^{2}$ Centro para el Desarrollo de la Nanociencia y Nanotecnología, CEDENNA, Santiago, Chile \\ ${ }^{3}$ Departamento de Ciencia de los Materiales, Universidad de Santiago de Chile, Santiago, Chile. \\ vparedes@unab.cl
}

The synthesis of coordination compounds based on $3 \mathrm{~d}$ cations has been of great interest not only for their various structures and topologies but also for their possible applications as functional materials in areas such as gas storage/adsorption, catalysis, magnetism, luminescence, among others. [1-3]

Two new coordination polymers based on $\mathrm{Co}^{\mathrm{II}}$ and $\mathrm{Ni}^{\mathrm{II}},\left\{\left[\mathrm{Co}(\mathrm{HL})(\mathrm{EtOH})_{2}\right]\left(\mathrm{ClO}_{4}\right)\right\} \mathrm{n}(\mathbf{1}),\left\{\left[\mathrm{Ni}(\mathrm{HL})(\mathrm{EtOH})_{2}\right]\left(\mathrm{ClO}_{4}\right)\right\}_{\mathrm{n}}(\mathbf{2})(\mathrm{H} 2 \mathrm{~L}=2-$ $\{[(E)-1 \mathrm{H}$-imidazol-4-ylmethylidene]amino\}benzoic acid), were synthesized using a new Schiff base ligand. Compounds $\mathbf{1}$ and 2 are isostructural presenting a one-dimensional helical chain arrangement and crystallizing in a $\mathrm{P} 21 / \mathrm{n}$ monoclinic space group. A hexacoordinated cation with an $\mathrm{MN}_{2} \mathrm{O}_{4}$ environment is present in the cationic fragment $\left[\mathrm{M}(\mathrm{HL})(\mathrm{EtOH})_{2}\right]^{+}$being the charge balanced by a $\mathrm{ClO}_{4}{ }^{-}$anion. Furthermore, the carboxylate group of HL- ligand is also acting as syn-anti bridge, producing the assembly of the $\left[\mathrm{M}(\mathrm{HL})(\mathrm{EtOH})_{2}\right]^{+}$fragments, thus generating a cationic chain growing through the $\mathrm{b}$ axis with an intercation $\mathrm{M} \cdots \mathrm{M}$ distance of 5.1257(13) $\AA$ and 5.164(4) $\AA$ for 1 and 2, respectively. The M-Ox distances are in the range of 2.060(3) $\AA$ to 2.136(4) $\AA$ for 1 and 1.988(3) to 2.107(4) $\AA$ for 2. Meanwhile, the M-Ny distances are 2.076(3) $\AA$ and 2.139(3) $\AA$ for 1 and 2.041(4) $\AA$ and 2.080(4) $\AA$ for 2. The resulting $\mathrm{MN}_{2} \mathrm{O}_{4}$ moiety presents an elongated octahedral geometry with higher bond distances in the axial position corresponding to the EtOH molecules. Magnetic susceptibility characterization in the $1.8-300 \mathrm{~K}$ range reveals intrachain antiferromagnetic interactions for $\mathbf{1}$ and ferromagnetic interaction for $\mathbf{2}$ with the presence of the zero-field splitting phenomenon in both compounds.

[1] F. J. Teixeira, L. S. Flores, L. B.L. Escobar, T.C. dos Santos, M. I. Yoshida, M.S. Reis, Stephen Hill, C. M. Ronconi, C. C. Corrêa, Inorg. Chim. Acta $511(2020)$.

[2] Y. N. Belokon, V. I. Maleev, M. North, V. A. Larionov, T. F. Savel'yeva, A. Nijland, Y. V. Nelyubina://doi.org/10.1021./cs400409d.

[3] R. Jangir, M. Ansari, D. Kaleeswaran, G. Rajaraman, M. Palaniandavar, R. Murugavel, ACS Catal. 9 (2019) 10940-10950.

\section{Keywords: Coordination Polymers; Magnetic Properties}

The authors acknowledge FONDECYT 1211394, CONICYT FONDEQUIP/PPMS/EQM130086-UNAB, Chilean-French International Associated Laboratory for Multifunctional Molecules and Materials-LIAM3-CNRS N 102 and CEDENNA, Financiamiento Basal, AFB180001. 